\title{
Farinha de folha de leucena (Leucaena leucocephala Lam. de wit) como fonte de proteína para juvenis de tambaqui (Colossoma macropomum CUVIER, 1818)
}

\author{
Geraldo PEREIRA JUNIOR ${ }^{1}$, Manoel PEREIRA FILHO², Rodrigo ROUBACH², Paula de Sousa BARBOSA², \\ Eduardo SHIMODA ${ }^{3}$
}

\begin{abstract}
RESUMO
O tambaqui (Colossoma macropomum) é um peixe onívoro, natural da bacia amazônica, que possui elevado valor comercial. Características de rusticidade e desempenho produtivo destacam esta espécie para criação em cativeiro. Contudo, em criações comerciais de peixes, os custos com alimentaçáo podem corresponder de 60 a $80 \%$ dos custos totais de produçáo, sendo a proteína o nutriente mais caro da dieta. O objetivo deste trabalho foi avaliar o desempenho produtivo de juvenis de tambaqui alimentados com raçóes contendo farinha de folha de leucena como fonte protéica. 240 juvenis foram distribuídos em 12 aquários experimentais $(350 \mathrm{~L})$, em um delineamento experimental inteiramente casualizado com quatro tratamentos $(0 \%$, $8 \%, 16 \%, 24 \%$ de inclusão de farinha de folha de leucena na ração) e três repetições. Foram determinados o ganho de peso, conversão alimentar aparente, taxa de crescimento específico, taxa de eficiência protéica e custo de produçáo do quilograma de peso vivo ganho. Para as variáveis estudadas, não houve diferença significativa $(\mathrm{p}>0,05)$ entre os tratamentos, indicando que é possível incluir até $24 \%$ de farinha de folha de leucena em raçōes para juvenis de tambaqui, sem comprometimento das variáveis estudadas, embora a substituição não tenha representado redução no custo de produção do quilograma de peixe.
\end{abstract}

PALAVRAS CHAVE: Piscicultura, nutrição de peixes, proteína.

\section{Leucaena leaf flour (Leucaena leucocephala Lam. of wit) as a protein source for juveniles of tambaqui (Colossoma macropomum Cuvier, 1818)}

\section{ABSTRACT}

The tambaqui (Colossoma macropomum) is an omnivorous fish native to the Amazon basin, which has high commercial value. Characteristics of rusticity and desirable growth in farming highlight this species for breeding in captivity. However, in commercial fish breeding, feed costs may represent $60-80 \%$ of total costs of production, being the protein the most expensive nutrient in the diet. The objective of this study was to evaluate the growth of juvenile tambaqui fed with diets containing leucaena leaf flour as protein source. A total of 240 juveniles were distributed in 12 experimental aquaria (350 L) in a completely randomized design with four treatments $(0 \%, 8 \%, 16 \%, 24 \%$ of inclusion of leucaena leaf flour in diet) and three replications. Weight gain, feed conversion ratio, specific growth rate, protein efficiency rate and cost of production per kilogram of live weight gained were calculated. For the studied variables, there was no significant difference $(p>0.05)$ among treatments, indicating that it is possible to include up to $24 \%$ of leucaena leaf flour in diets for juveniles of tambaqui, without compromising the variables studied, although the replacement has not represented reduction in cost of production per kilogram of fish.

KEYWORDS: Fish breeding, fish nutrition, protein.

\footnotetext{
1 Universidade Federal do Amazonas - UFAM. Av. General Rodrigo Octávio Jordão Ramos, 3000, Campus Universitário, Coroado I - Manaus, AM- Brasil. Email: geraldoinpa@hotmail.com

2 Instituto Nacional de Pesquisas da Amazônia - INPA: Av. André Araújo, 2936, Petrópolis, Aleixo, 69083-000 - Manaus, AM - Brasil. Emails: pmanoel@inpa.gov.br, rodrigo.roubach@mpa.gov.br, manatee_psbd@hotmail.com

${ }^{3}$ Universidade Candido Mendes - UCAM: Rua: Anita Pessanha, 100, Parque São Caetano - Campos dos Goytacazes, RJ - Brasil. Email:shimoda@ucam-campos.br
} 


\section{INTRODUÇÃO}

O tambaqui é uma excelente opção para a piscicultura nacional, pois apresenta várias características favoráveis ao confinamento. É destacada a sua grande rusticidade, tolerância às baixas concentraçóes de oxigênio dissolvido na água, boa aceitação de subprodutos agroindustriais, boa conversão alimentar, boa adaptação ao cultivo em cativeiro com crescimento relativamente rápido (Graef 1995) e disponibilidade de juvenis para comercialização (Batista e Petrere-Júnior 2003).

Para se obter bons resultados em cultivos comerciais de peixes, o alimento consumido pelas espécies deve conter todos os nutrientes necessários ao seu desenvolvimento. Porém é necessário atentar para os gastos com a alimentação, que podem corresponder de 60 a $80 \%$ do custo total de produção em uma piscigranja (Pereira-Filho 1995), sendo a proteína o nutriente mais caro da dieta (Faria et al. 2001; Santos et al. 2009).

A farinha de peixe tem sido tradicionalmente usada como fonte de proteína em raçóes para peixes (Hardy 1999). Entretanto, devido à falta de padronização deste produto e ao seu alto custo comercial, tem-se buscado fontes alternativas de proteína para elaboração de dietas para peixes (El-Saidy e Gaber 2003; Furuya et al. 2004; Medri et al. 2005).

Os alimentos de origem vegetal vêm sendo usados com maior freqüência na alimentação animal devido ao seu custo mais baixo e maior disponibilidade que a farinha de peixe, podendo substituí-la de forma parcial ou total (Kubitza 1999; Carter e Hauler 2000). A utilização dos ingredientes de origem vegetal tem sido muito estudada na elaboração de raçôes para peixes comerciais (Soares et al. 2000; Soares et al. 2001; Galdioli et al. 2002; Silva et al. 2003).

A leucena (Leucaena leucocephala) é uma leguminosa originária da América Central, México, sendo encontrada em muitas regiôes tropicais do mundo (Silva et al. 2007). Trata-se de uma espécie arbustiva, perene, que apresenta raízes profundas, característica que lhe confere excelente tolerância à seca, sendo considerada uma planta bastante rústica (Prates $e t$ al. 2000). Além da rusticidade, as possibilidades de uso desta espécie contribuíram para sua ampla dispersão. A leucena é utilizada na recuperação de áreas degradadas, adubação verde, produção de madeira, produção de carvão vegetal, sombreamento e quebra vento (Oliveira 2008). Entretanto, o grande destaque desta planta é a sua utilização na alimentação de animais ruminantes e monogástricos (Almeida et al. 2006; Arruda et al. 2010).

A leucena apresenta uma produção anual média de 20 a 25 toneladas de forragem por hectare, com altos teores de proteína bruta (26\%) de bom valor nutricional (Pires et al. 2001). Esta leguminosa possui palatabilidade apreciável pelos animais ruminantes e monogástricos (Scapinello et al. 2000; Barreto et al. 2010).

Porém a leucena possui um aminoácido não protéico, conhecido como mimosina, que é um fator antinutricional inibidor competitivo da produçáo do hormônio Tiroxina (Almeida et al. 2006), produzido na tireóide. Por este motivo, o uso desta leguminosa tem sido limitado na alimentação de algumas espécies animais monogástricos (Oliveira et al. 2000). Entretanto, a quantidade de mimosina na folha de leucena pode ser reduzida com o tratamento térmico do material (Tangendjaja et al. 1994). Estudos demonstraram que é possível utilizar a leucena como fonte de proteína para ruminantes (Longo 2002; Barreto et al. 2010) e para monogástricos (Mutayoba et al. 2003; Arruda et al. 2010), proporcionando aumento na produtividade.

$\mathrm{Na}$ literatura podemos encontrar relatos de que o potencial nutritivo da folha de leucena em dietas para peixes é conflitante. Melhora no crescimento e performance de peixes alimentados com ração contendo folha de leucena foi relatado para espécies de tilápia (Ghatnekar et al. 1982; Santiago et al. 1988; Rocha 2004; Segundo et al. 2006) e para Labeo rohita (Bairagi et al. 2004). Por outro lado, apresentou piora no desempenho zootécnico de peixes alimentados com dietas contendo leucena foi reportada para espécies de tilápia (Jackson et al. 1982; Wee e Wang 1987) e carpa comum (Mohire e Devaraj 1990; Hasan et al. 1997).

\section{OBJETIVO}

O objetivo deste trabalho foi avaliar o desempenho produtivo e o custo de produçáo do quilograma de juvenis de tambaqui alimentados com raçóes contendo farinha de folha de leucena como fonte protéica.

\section{MATERIAL E MÉTODOS}

O experimento foi conduzido na Coordenação de Pesquisas em Aqüicultura - CPAQ/INPA no período de outubro até dezembro de 2005, com duração de 60 dias. O desempenho zootécnico dos animais experimentais e o custo da ração por quilograma de peso vivo ganho foram avaliados.

Foram utilizados 250 juvenis de tambaqui, com peso médio inicial de 41,1 $\pm 4,83 \mathrm{~g}$, distribuídos em 12 unidades experimentais, em um delineamento experimental inteiramente casualizado com quatro tratamentos e três repetiçôes. As raçôes foram formuladas de modo a serem isoprotéicas (32\% PB) e isocalóricas ( $3500 \mathrm{kcal} \mathrm{ED} / \mathrm{kg})$, com níveis crescentes $(0,8,16$ e $24 \%)$ de inclusão de farinha de folha de leucena, correspondendo aos tratamentos I, II, III e IV, respectivamente.

Cada unidade experimental foi representada pela média de peso de 20 indivíduos acondicionados em um aquário 
experimental com capacidade para $350 \mathrm{~L}$, abastecido com água de poço artesiano, com renovação e aeraçáo constantes e monitoramento dos parâmetros físico-químicos da água.

O sistema de entrada e saída de água foi individual para cada aquário, com renovação diária de $10 \%$ do volume total por dia. Os aquários foram sifonados duas vezes por semana ou sempre que fosse verificada visualmente grande deposição de fragmentos sólidos.

Para secagem das folhas, o material vegetal foi colocado em uma estufa a uma temperatura de $40{ }^{\circ} \mathrm{C}$, durante 24 horas. Esta temperatura pode ter ativado enzimas da própria planta para degradar a mimosina (autólise), conforme reportado por Tangendjaja et al. (1994). Após a desidratação, os folíolos foram retirados e moídos em moedor de carne, com matriz fina de $6 \mathrm{~mm}$.

Para elaboração das raçóes experimentais, os ingredientes foram moídos individualmente em um moedor de carne, com matriz fina de $1 \mathrm{~mm}$. Posteriormente, os ingredientes foram misturados, umedecidos e processados em moedor de carne, com matriz de $6 \mathrm{~mm}$, para a formaçáo dos peletes. Para secagem, foi usada uma estufa com circulaçáo forçada de ar, a temperatura constante de $30{ }^{\circ} \mathrm{C}$. As raçóes foram acondicionadas em sacos plásticos de $2 \mathrm{~kg}$ e mantidas em freezer a $5{ }^{\circ} \mathrm{C}$ negativos.

Para aferir a homogeneidade dos animais experimentais, foi realizada ao início do experimento, uma biometria tomando-se o peso em grama, com uma balança eletrônica com $0,5 \mathrm{~g}$ de precisão. Posteriormente foi realizado um sorteio, para distribuiçáo aleatória dos juvenis de tambaqui nos aquários experimentais, onde receberam os tratamentos a que foram submetidos.

Para adaptação às condiçóes experimentais, os peixes foram alimentados com uma dieta controle contendo $32 \%$ de proteína bruta, durante uma semana. Após esta fase, os animais foram submetidos a um jejum de 24 horas e, posteriormente, alimentados duas vezes ao dia (8:30 e 16:30 h) com a ração experimental, até a saciedade aparente, sendo registrado o consumo diário de ração de cada unidade experimental, para determinação dos índices zootécnicos.

No início e no final do experimento foram realizadas as medidas individuais de peso $(\mathrm{g})$ dos peixes de cada unidade experimental. Para facilitar este trabalho, foi usada uma solução com anestésico benzocaína a $100 \mathrm{mg} . \mathrm{L}^{-1}$ (Gomes et al. 2001).

A cada sete dias foram realizadas, em todas as unidades experimentais, medidas de condutividade elétrica, amônia e nitrito $\left(\mathrm{mg} . \mathrm{L}^{-1}\right)$, sendo utilizados um condutivímetro digital, o método do endofenol e colorimetria, respectivamente. Já as medidas de temperatura da água, oxigênio dissolvido e $\mathrm{pH}$ foram tomadas diariamente pela manhã $(9 \mathrm{~h})$, sendo as duas primeiras determinadas com oxímetro e a última com um medidor de $\mathrm{pH}$ digital de bancada.

O desempenho dos peixes foi avaliado em termos de ganho de peso (Gp, g), índice de conversão alimentar $\left(\mathrm{CA}, \mathrm{g} \mathrm{g}^{-1}\right)$, taxa de eficiência proteica (TEP) e taxa de crescimento específico (TCE). Os parâmetros de desempenho foram calculados de seguinte forma: $G p=P_{i}-P_{f}(g)$, $P_{i}$ é o peso inicial dos peixes e $\mathrm{P}_{\mathrm{f}}$ é o peso final dos peixes no dia t; $\mathrm{CA}=$ consumo da dieta (g) / ganho de peso $(\mathrm{g}) ; \mathrm{TEP}=$ ganho de peso $(\mathrm{g}) /$ proteína consumida (g) (Jauncey e Ross 1982); TCE $=100^{*}[(\ln \mathrm{Pf}-\ln$ $\mathrm{Pi} / \mathrm{t}$ ], Pf é o Peso final e Pi é o Peso inicial (g), ln éo Logaritmo natural e $\mathrm{t}$ são os dias de experimento.

Para avaliar a viabilidade econômica da inclusão de farinha de folha de leucena nas raçóes foi determinado o custo médio do alimento por quilograma de peso vivo ganho, segundo Bellaver et al. (1985).

$$
\mathrm{Yi}=\mathrm{Qi} \times \mathrm{Pi} / \mathrm{Gi}
$$

Em que: $\mathrm{Yi}$ = custo médio da raçáo por quilograma ganho no i-ésimo tratamento, $\mathrm{Q} i=$ quantidade média de ração consumida no i-ésimo tratamento, $\mathrm{Pi}=$ preço médio por quilograma de ração utilizada no i-ésimo tratamento, $\mathrm{Gi}=$ ganho médio de peso do i-ésimo tratamento.

As análises da composiçáo centesimal dos ingredientes e raçôes foram realizadas no Laboratório de Nutrição de Peixes/ CPAQ/INPA, segundo metodologia descrita pela A.O.A.C. (1997).

Para avaliar os efeitos dos tratamentos foi usada a análise de variância (ANOVA) a 5\% de probabilidade, sendo utilizado o aplicativo estatístico SYSTAT.

\section{RESULTADOS E DISCUSSÃO}

Os valores médios para as variáveis físico-químicas da água não apresentaram diferenças estatísticas significativas $(\mathrm{p}>0,05)$ entre os tratamentos, conforme apresentado na Tabela 3. Os valores observados estáo dentro dos recomendados para o tambaqui (Kubitza, 2003).

Durante o período experimental observou-se que a água das unidades experimentais que receberam raçóes contendo farinha de folha de leucena apresentou coloração escura. Provavelmente, esta coloração foi influenciada pelos pigmentos da folha de leucena. Nestas mesmas unidades, foi observada uma grande quantidade de sedimentos orgânicos depositados no fundo, sendo necessária uma maior freqüência de limpeza.

Os peixes alimentados com as raçôes experimentais contendo farinha de folha de leucena apresentaram cor da pele diferente dos peixes alimentados com a raçấo sem este ingrediente. À medida que os níveis de inclusão da farinha de folha de leucena aumentavam nas dietas, aumentava, de 
maneira proporcional, o tom da coloração verde-amarelado dos peixes.

Não houve diferença significativa $(\mathrm{p}>0,05)$ para as variáveis de desempenho produtivo analisadas. Os valores médios encontrados para ganho de peso, consumo de ração, conversão alimentar aparente, taxa de eficiência protéica e taxa de crescimento específico estão apresentados na Tabela 5. Durante o período experimental não foi registrada mortalidade em nenhum dos tratamentos.

Os resultados para a variável ganho de peso encontrados neste estudo, sugerem que o tambaqui é um peixe capaz de aproveitar bem raçôes contendo farinha de folha de leucena, o que indica que náo ocorreu impactos negativos relacionados a mimosina.

Estes resultados concordam com os obtidos por Bairagi $e t$ al. (2004) para Labeo rohita, que observaram melhores valores para este índice quando peixes foram alimentados com dietas contendo farinha de folha de leucena inoculada com bactérias intestinais de peixes. Segundo este autor, as folhas de leucena inoculadas com bactérias intestinais de peixe apresentaram decréscimos nos conteúdos de mimosina e tanino, sugerindo que tais microorganismos são capazes de degradar estes fatores antinutricionais.

Também concordam com Wee e Wang (1987) e Rocha (2004), que alimentaram tilápias Oreochromis niloticus com farinha de folha de leucena e verificaram que é possível incluir este ingrediente nas raçôes, sem comprometimento do ganho de peso. Para estes autores, o bom desempenho das tilápias está relacionado com a degradação da mimosina durante o processamento da farinha de folha de leucena. Este fato também foi reportado por Pascual e Penäflorida (1979) e Vogt et al. (1986).

Por outro lado, piores resultados para o ganho de peso foram encontrados por Jackson et al. (1982), Santiago et al. (1988) e Hasan et al. (1997), os quais observaram redução no peso final dos peixes com o aumento dos níveis de farinha de folha de leucena nas dietas. Para estes autores, a mimosina foi responsável pelos baixos valores de ganho de peso. Segundo eles, a não utilização de métodos para diminuir os teores

Tabela 1 - Composição centesimal dos ingredientes utilizados na formulação das rações experimentais

\begin{tabular}{lcccccc}
\hline Ingredientes & $\begin{array}{c}\text { MS } \\
(\%)\end{array}$ & $\begin{array}{c}\text { PB } \\
(\%)\end{array}$ & $\begin{array}{c}\text { EE } \\
(\%)\end{array}$ & $\begin{array}{c}\text { FB } \\
(\%)\end{array}$ & $\begin{array}{c}\text { ENN } \\
(\%)\end{array}$ & $\begin{array}{c}\text { Cinzas } \\
(\%)\end{array}$ \\
\hline Farinha de peixe & 87,6 & 62,1 & 8,5 & - & - & 13,1 \\
Milho & 89,5 & 8,1 & 3,6 & 1,6 & 75,5 & 0,5 \\
Farelo de trigo & 90,2 & 16,0 & 3,4 & 4,8 & 61,1 & 4,6 \\
Farelo de glútem de milho & 91,2 & 39,4 & 0,4 & 0,6 & 48,1 & 2,0 \\
Óleo de soja & 100,0 & - & 10,0 & - & - & - \\
Farinha de folha de leucena & 90,3 & 21,0 & 3,5 & 12,0 & 48,6 & 6,1
\end{tabular}

MS = Matéria seca; $\mathrm{PB}=$ proteína bruta; $\mathrm{EE}=$ extrato etéreo; $\mathrm{FB}$ = fibra bruta; $\mathrm{ENN}$ $=$ extrativo não nitrogenado. de mimosina nas folhas de leucena pode ter sido a causa da presença deste fator antinutricional.

Não houve diferença significativa no consumo de ração, sugerindo que o tambaqui possui boa aceitação às raçóes contendo farinha de folha de leucena. Isso foi observado diariamente durante os horários de alimentação, sendo que os peixes que receberam dietas contendo este ingrediente apresentaram atividade intensa durante o fornecimento da ração. Isto pode ser explicado pelo hábito alimentar do tambaqui já que tanto alimentos de origem animal quanto vegetal fazem parte da sua dieta. A palatabilidade da leucena também pode ter contribuído para os valores de consumo de ração encontrados neste estudo.

Os resultados para a variável consumo de ração, encontrados nesta pesquisa, corroboram com os encontrados por Bairagi et al. (2004) que não verificaram diminuição no consumo de ração com níveis crescentes de inclusão de farinha de folha de leucena nas dietas. Provavelmente estes resultados estão relacionados com ausência de mimosina nas raçóes, já que as folhas de leucena foram submetidas ao processo de fermentação com bactéria intestinal de peixe. Por outro lado, discordam dos resultados observados por Jackson (1982) e Wee e Wang (1987), que encontraram diminuição no consumo de ração por tilápias com aumento dos níveis de farinha de folha de leucena, sendo atribuído à mimosina o menor desempenho para esta variável.

Os valores para conversáo alimentar aparente encontrados, em todos os tratamentos $(2,6 \pm 0,2$ a 2,8 $\pm 0,9$ - Tabela

Tabela 2 - Composição percentual e química das dietas experimentais com níveis de inclusão $(0,8,16$ e 24\%) de farinha de folha de leucena

\begin{tabular}{lcccc}
\hline \multirow{2}{*}{ Ingredientes } & \multicolumn{4}{c}{ Quantidade (\%) } \\
\cline { 2 - 5 } & $\mathrm{T} 1$ & $\mathrm{~T} 2$ & $\mathrm{~T} 3$ & $\mathrm{~T} 4$ \\
\hline Farinha de peixe & 36,0 & 33,0 & 31,0 & 28,0 \\
Milho & 27,0 & 43,0 & 40,0 & 30,0 \\
\hline Farelo de trigo & 34,0 & 7,0 & 0,0 & 1,0 \\
\hline Farelo de glútem de milho & 0,0 & 6,0 & 8,0 & 10,0 \\
\hline Óleo de soja & 2,0 & 2,0 & 4,0 & 6,0 \\
\hline Farinha de folha de leucena & 0,0 & 8,0 & 16,0 & 24,0 \\
\hline Premix & 1,0 & 1,0 & 1,0 & 1,0 \\
\hline Total & 100,0 & 100,0 & 100,0 & 100,0 \\
\hline Matéria seca (\%) & 92,5 & 91,5 & 91,7 & 91,6 \\
\hline Proteína bruta (\%) & 30,5 & 32,8 & 33,1 & 35,3 \\
\hline Extrato etéreo (\%) & 6,6 & 6,4 & 7,6 & 8,7 \\
Cinzas (\%) & 7,1 & 5,5 & 5,3 & 5,4 \\
\hline Fibra bruta (\%) & 3,9 & 2,6 & 4,2 & 4,4 \\
\hline ENN (\%) & 44,4 & 44,2 & 41,5 & 37,8 \\
\hline Energia bruta (Kcal/kg) & 4168 & 4270 & 4289 & 4364 \\
\hline EB:PB & 13,6 & 13,0 & 12,95 & 12,3 \\
\hline
\end{tabular}

$\mathrm{PB}=$ proteína bruta; $\mathrm{EB}=$ energia bruta; $\mathrm{ENN}=$ extrativo não nitrogenado. 
5), foram considerados ruins para o cultivo de tambaqui, quando comparado aos trabalhos de outros autores (Terrazas et al. 2002; Mendonça et al. 2009; Lemos et al. 2011). Isso pode estar relacionado com a baixa atividade física dos peixes durante o período experimental. Hackbarth (2004) verificou que o matrinxâ (Brycon cephalus), à semelhança do tambaqui também uma espécie reofílica, submetidas a exercícios físicos sustentados, fez um melhor uso das raçóes ofertadas, o que foi confirmado com a diminuição dos valores de conversão alimentar aparente em até 54\%. Resultado semelhante foi mencionado por Davison (1997), para truta (Onchorhynchus mykiss).

Apesar dos resultados encontrados nesta pesquisa, para a variável conversão alimentar aparente, serem considerados altos para o tambaqui, não houve diferença significativa ( $>0,05)$ entre os tratamentos, concordando com os obtidos por Bairagi et al. (2004) ao alimentarem Labeo rohita com níveis crescentes de farinha de folha de leucena nas raçóes. Para estes autores, a inoculação da folha de leucena com bactérias intestinais de peixe, proporcionou diminuição no teor de fibra bruta e aumento na quantidade de aminoácidos livres, melhorando a qualidade do alimento e favorecendo boa conversão alimentar.

Por outro lado, discordam dos resultados observados por Jackson et al. (1982), Wee e Wang (1987) e Santiago et al. (1988), para tilápia, e Hasan et al. (1997), para carpa comum, que observaram piora na conversão alimentar dos peixes com a inclusão de farinha de folha de leucena nas dietas. Estes autores atribuem os piores resultados para conversão alimentar aparente à baixa digestibilidade das raçóes contendo farinha de folha de leucena.

Os resultados para a taxa de crescimento específico obtidos neste trabalho concordam com os obtidos por Bairagi et al.

Tabela 3 - Parâmetros de qualidade da água de juvenis de tambaqui alimentados com rações contendo níveis de inclusão (0, 8, 16 e 24\%) de farinha de folha de leucena (média \pm desvio padrão)

\begin{tabular}{|c|c|c|c|c|}
\hline \multirow{2}{*}{ Parâmetros } & \multicolumn{4}{|c|}{ Rações experimentais } \\
\hline & $\mathrm{T} 1$ & T2 & T3 & $\mathrm{T} 4$ \\
\hline Oxigênio (OD) (mg L-1) & $5,7 \pm 0,2$ & $5,5 \pm 0,1$ & $5,7 \pm 0,1$ & $6,0 \pm 0,4$ \\
\hline $\begin{array}{l}\text { Condutividade (mS. } \\
\mathrm{cm}^{-2} \text { ) }\end{array}$ & $23,3 \pm 0,6$ & $23,8 \pm 0,7$ & $23,5 \pm 0,5$ & $23,6 \pm 0,3$ \\
\hline $\mathrm{pH}$ & $5,2 \pm 0,0$ & $5,3 \pm 0,0$ & $5,3 \pm 0,0$ & $5,2 \pm 0,0$ \\
\hline$\left[\mathrm{NH}_{3}\right]_{\text {total }}\left(\mathrm{mg} \mathrm{L}^{-1}\right)$ & $0,3 \pm 0,0$ & $0,3 \pm 0,1$ & $0,3 \pm 0,0$ & $0,3 \pm 0,0$ \\
\hline Nitrito $\left(\mathrm{NO}_{2}\right)\left(\mathrm{mg} \mathrm{L}^{-1}\right)$ & $0,0 \pm 0,0$ & $0,1 \pm 0,0$ & $0,0 \pm 0,0$ & $0,0 \pm 0,0$ \\
\hline Dureza (mg de $\mathrm{CaCO}_{3} \mathrm{~L}^{-1}$ ) & $3,7 \pm 0,0$ & $3,8 \pm 0,0$ & $3,7 \pm 0,0$ & $3,5 \pm 0,0$ \\
\hline Alcal. (mg de $\left.\mathrm{CaCO}_{3} \mathrm{~L}^{-1}\right)$ & $5,2 \pm 0,0$ & $5,4 \pm 0,0$ & $5,1 \pm 0,0$ & $5,1 \pm 0,0$ \\
\hline Temperatura $\left({ }^{\circ} \mathrm{C}\right)$ & $28,2 \pm 0,0$ & $28,2 \pm 0,0$ & $28,2 \pm 0,0$ & $28,0 \pm 0,0$ \\
\hline
\end{tabular}

(2004), que não observaram diferenças significativas para esta variável quando peixes foram alimentados com dietas contendo farinha de folha de leucena. Contudo, discordam dos resultados encontrados por Rocha (2004), o qual encontrou diferenças significativas para taxa de crescimento específico com aumento de farinha de folha de leucena nas dietas.

Os resultados encontrados nesta pesquisa indicam que o tambaqui foi eficiente na utilizaçáo da proteína contida na dieta, independente da origem. Estes resultados assemelham-se aos obtidos, para rohu Labeo rohita, por Bairagi et al. (2004), que não verificaram diferenças significativas para esta variável com a inclusão de farinha de folha de leucena nas dietas. Entretanto, diferem dos encontrados por Jackson et al. (1982), Wee e Wang (1987) e Rocha (2004), que observaram redução na taxa de eficiência protéica dos peixes com aumento dos níveis de farinha de folha de leucena nas rações.

As dietas experimentais apresentaram valores muito próximos para os custos de produção. Apesar da pouca variaçáo numérica entre os tratamentos, a ração IV foi a mais barata $(\mathrm{R} \$ 0,99 / \mathrm{kg})$, seguida da raçáo I $(\mathrm{R} \$ 1,01 / \mathrm{kg})$, raçáo III ( $\mathrm{R}$ \$ $1,03 / \mathrm{kg})$ e ração II $(\mathrm{R} \$ 1,04 / \mathrm{kg})$, respectivamente.

Não houve queda no custo de produção do quilograma de peixe com a inclusão da farinha de folha de leucena nas raçôes. O quilograma de peixe mais barato foi do tratamento I (R\$3,21). Já o quilograma mais caro foi do tratamento II $(\mathrm{R} \$ 3,67)$, seguido pelo tratamento III $(\mathrm{R} \$ 3,52)$ e tratamento IV $(\mathrm{R} \$ 3,28)$, respectivamente.

Apesar dos níveis de substituição analisados neste trabalho não terem proporcionado diminuiçáo nos custos de produção desta espécie, observa-se que a farinha de folha de leucena foi o ingrediente mais barato $(\mathrm{R} \$ 0,16 / \mathrm{kg})$ utilizado na elaboração das dietas experimentais, conforme apresentado na Tabela 4. Entretanto, para promover um balanceamento das raçōes experimentais, à medida que aumentavam os teores de farinha de folha de leucena nas dietas, aumentavam também os níveis de outros ingredientes, a exemplo do milho, farelo de glútem de milho e óleo de soja, conforme apresentado na Tabela 2. Estes ingredientes apresentam-se com elevado custo, proporcionando um aumento considerável no custo de produção das dietas contendo farinha de folha de leucena.

Sendo assim, é necessário que outras fontes alternativas com potencialidades de uso na elaboração de dietas para peixes sejam identificadas e estudadas na região amazônica.

\section{CONCLUSÃO}

É viável a inclusão de até $24 \%$ de farinha de folha de leucena em raçôes de juvenis de tambaqui, sem que haja comprometimento dos parâmetros de desempenho avaliados neste trabalho. Além disso, as inclusôes, nos níveis estudados, não resultaram em redução nos custos de produção do quilograma de peixe. 
Tabela 4 - Custo de produção das dietas experimentais com níveis de inclusão (0, 8, 16 e 24\%) de farinha de folha de leucena e 0 custo médio da ração por quilograma de peso vivo ganho

\begin{tabular}{lcccccc}
\hline \multirow{2}{*}{ Ingrediente } & & & \multicolumn{4}{c}{ Custo das rações experimentais (R\$) } \\
\cline { 5 - 7 } & Unidade & Valor $(\mathrm{R} \$)$ & $\mathrm{T} 1$ & $\mathrm{~T} 2$ & $\mathrm{~T} 3$ & $\mathrm{~T}$ \\
\hline Farinha de peixe & $\mathrm{kg}$ & 1,80 & 64,80 & 59,40 & 55,80 & 50,40 \\
Milho & $\mathrm{kg}$ & 0,45 & 12,15 & 19,35 & 18,45 & 14,40 \\
Farelo de trigo & $\mathrm{kg}$ & 0,25 & 8,50 & 1,75 & - & 0,25 \\
\hline Premix & $\mathrm{kg}$ & 14,00 & 14,00 & 14,00 & 14,00 & 14,00 \\
\hline Farelo glúten de milho & $\mathrm{kg}$ & 1,00 & - & 6,00 & 8,00 & 10,00 \\
Óleo de soja & $\mathrm{L}$ & 1,20 & 2,40 & 2,40 & 4,80 & 7,20 \\
\hline Farinha leucena & $\mathrm{kg}$ & 0,16 & - & 1,28 & 2,40 & 3,52 \\
TOTAL (100 kg) & - & - & 101,85 & 104,18 & 103,45 & 99,77 \\
Custo/kg de ração & - & - & 1,01 & 1,04 & 1,03 & 0,99 \\
Custo médio/kg/PV ganho & - & - & 3,21 & 3,67 & 3,52 & 3,28 \\
\hline
\end{tabular}

PV = peso vivo

Tabela 5 - Desempenho dos juvenis de tambaqui alimentados com rações contendo níveis de inclusão (0, 8, 16 e 24\%) de farinha de folha de leucena (média \pm desvio padrão)

\begin{tabular}{|c|c|c|c|c|c|c|c|}
\hline \multirow{2}{*}{ Trat. } & \multirow[b]{2}{*}{$P_{\text {inicial }}(g)$} & \multicolumn{6}{|c|}{ Variáveis de desempenho } \\
\hline & & $P_{\text {final }}(g)$ & GP $(g)$ & CR (g) & CAA & TCE \% & TEP \% \\
\hline I & $41,1 \pm 0,4$ & $92,8 \pm 5,9$ & $51,7 \pm 6,1$ & $1,8 \pm 0,1$ & $2,8 \pm 0,2$ & $1,3 \pm 0,1$ & $1,4 \pm 0,0$ \\
\hline II & $41,1 \pm 1,3$ & $94,3 \pm 4,3$ & $53,0 \pm 4,1$ & $2,0 \pm 0,1$ & $2,6 \pm 0,2$ & $1,3 \pm 0,0$ & $1,1 \pm 0,0$ \\
\hline III & $40,7 \pm 1,0$ & $90,7 \pm 4,1$ & $52,0 \pm 9,6$ & $1,9 \pm 0,1$ & $2,8 \pm 0,9$ & $1,3 \pm 0,1$ & $1,0 \pm 0,5$ \\
\hline IV & $41,3 \pm 0,2$ & $96,6 \pm 7,6$ & $55,3 \pm 7,4$ & $2,1 \pm 0,1$ & $2,7 \pm 0,1$ & $1,3 \pm 0,0$ & $1,1 \pm 0,0$ \\
\hline
\end{tabular}

$\mathrm{GP}=$ ganho de peso, $\mathrm{CR}=$ consumo de ração, $\mathrm{CAA}=$ conversão alimentar aparente, $\mathrm{TCE}=$ taxa de crescimento específico, TEP $=$ taxa de eficiência protéica

\section{AGRADECIMENTOS}

A Fundação de Amparo à Pesquisa do Estado do Amazonas (FAPEAM) pela bolsa de estudos e suporte financeiro para execução do projeto. Ao Programa de Pós-Graduação do Instituto Nacional de Pesquisas da Amazônia (INPA) pela oportunidade.

\section{BIBLIOGRAFIA}

Almeida, A.P; Kommers, G.D.; Nogueira, A.P.; Marques, B.P. Lemos, R.A. 2006. Avaliação do efeito tóxico de Leucaena leucocephala (Leg. Mimosoideae) em ovinos. Pesquisa Veterinária Brasileira, 26: 190-194.

A.O.A.C. 1997. Official Methods of Analysis. 17th. Ed. Gaithersburg, USA: Association of Official Analytical Chemists Int.

Arruda, A.M.V.; Melo, A.S.; Oliveira, V.RM.; Souza, D.H.; Dantas, F.D.T.; Oliveira, J.F. 2010. Avaliaçáo nutricional do feno de leucena com aves caipiras. Acta Veterinaria Brasilica, 4: 162-167.

Bairagi, A.; Ghosh, K.S.; Sem, S.K.; Ray, A.K. 2004. Evaluation of the nutritive value of Leucaena leucocephala leaf meal, inoculated with fish intestinal bacteria Bacillus subtilis and Bacillus circulans in formulated diets for rohu, Labeo rohita. Aquaculture Research, 35: 436-446.

Barreto, M.L.J.; Lima-Júnior, D.M.; Oliveira, J.P.F.; Rangel, A.H.N. Aguiar, E.M. 2010. Utilização de leucena (Leucaena leucocephala) na alimentação de ruminantes. Revista Verde, 5: 7-16.
Batista, V.S.; Petrere Júnior, M. 2003. Characterization of the commercial fish production landed at Manaus, Amazonas State, Brazil. Acta Amazônica, 33: 53-66.

Bellaver, C.; Fialho, E.T.; Protas, J.F.S. 1985. Radícula de malte na alimentação de suínos em crescimento e terminação. Pesquisa Agropecuária Brasileira, 20: 969-974.

Carter, G.G. ; Hauler, R.C. 2000. Fish meal replacement by plant meals in extruded feeds for Atlantic Salmon, Salmo solar L. Aquaculture, 185: 299-311.

Davison, W. 1997. The effects of exercise traing on teleost fish, a review of recent literature. Comp. Biochemistry Physiology, 117: 67-75.

El-Saidy , D.M.S.; Gaber, M.A. 2003. Replacement of fish a mixture of different plant protein sources in juvenile Nile tilapia, Oreochromis niloticus (L.) diets. Aquaculture Research, 34: 1119-1127.

Faria, A.C.E.; Hayashi, C.; Soares, C.M. 2001. Substituição parcial e total da farinha de peixe pelo farelo de soja em dietas para alevinos de piavuçu, Leporinus macrocephalus (Garavelho \& Britski, 1988). Acta Scientiarum, 23: 835-840.

Furuya, W.M.; Hayashi, C.; Furuya, V.R.B.; Sakaguti, E.S.; Botaro, D. 2004. Farelo de soja em raçóes para juvenis de tilápia do Nilo (Oreochomis niloticus). Acta Scientiarum, 26: 203-207.

Galdioli, E.M.; Hayashi, C.; Soares, C.M.; Furuya, V.R.B.; Faria, A.C.A. 2002. Substituiçẫo da Proteína do Farelo de Soja pela Proteína do Farelo de Canola em Raçóes para Alevinos 
de Curimbatá (Prochilodus lineatus V.). Revista Brasileira de Zootecnia, 31: 552-559.

Ghatnekar, S.D.; Auti, D.G.; Kamat, V.S. 1982. Feeding Leucaena leucocephala to Mozambique tilapia and Indian major carp. Australian Veterinary Jornal, 52: 257-268.

Gomes, L.C.; Chippari-Gomes, A.R.; Lopes, N.P.; Roubach, R.; Araújo-Lima, C.A.R.M. 2001. Eficacy of benzocaime as an anesthetic in juvenile tambaqui, Colossoma macropomum. Jornal of the World Aquaculture society, 32: 426-431.

Graef, E.W. 1995. As espécies de peixes com potencial para criação no Amazonas, p. 29-43. In: Val, L.A. \& Honczark, A. (Eds). Criando peixes na Amazônia. Instituto Nacional de Pesquisas da Amazônia, Manaus, Amazonas.

Hackbarth, A. 2004. Respostas metabólicas e de crescimento de matrinxās (Brycon cephalus Gunther, 1869) submetidos ao exercício sustentado. Dissertação de mestrado, Universidade Federal de São Carlos. 88pp.

Hardy, R.W. 1999. Aquaculture's rapid growth requirements for alternate protein sources. Feed Management, 50: 25-28.

Hasan, M.R.; Macintosh, D.J.; Jauncey, K. 1997. Evaluation of some plant ingredients as dietary protein sources for common carp (Cyprinus carpio) fry. Aquaculture, 151: 55-70.

Jackson, A.J.; Capper, B.S.; Matty, A.J. 1982. Evaluation of some plant proteins in complete diets for the tilapia Sarotherodon mossambicus. Aquaculture, 27: 97-109.

Jauncey, K.; Ross, B. 1982. A guide to tilapia feeds and feeding. Scotland, University of Stirling. 111pp.

Kubitza, F. 1999. Nutrição e alimentação dos peixes cultivados. $3^{0}$ edição, Jundiaí, SP, $123 \mathrm{pp}$.

Kubitza, F. 2003. Qualidade da água no cultivo de peixes e camaröes. Jundiaí. SP, 229pp.

Lemos, M.V.A.; Guimarães, I.G.; Miranda, E.C. 2011. Farelo de coco em dietas para o tambaqui (Colossoma macropomum). Revsita Brasileira Saúde Produção Animal, 12: 188-198.

Longo, C. 2002. Avaliação do uso de Leucaena leucocephala em dietas de ovinos da raça Santa Inês sobre o consumo, a digestibilidade e a retenção de nitrogênio. Dissertação de mestrado, Universidade de São Paulo, Piracicaba, São Paulo. 62pp.

Medri, V.; Medri, W.; Filho, M.C. 2005. Desempenho de tilápias nilóticas (Oreochromis niloticus) alimentadas com diferentes níveis de proteína de levedura de destilaria em tanques-rede. Acta Scientiarum, 27: 221-227.

Mendonça, P.P.; Ferreira, R.A.; Vidal-Junior, M.V.; Andrade, D.R.; Santos, M.V.B.; Ferreira, A.V.; Rezende, F.P. 2009. Influência do fotoperíodo no desenvolvimento de juvenis de tambaqui (Colossoma macropomum). Archivos de Zootecnia, 58: 323-331.

Mohire, K.L.; Devaraj, K.V. 1990. Suplemental feeds containg subabul leaf meal for rearing common carp. Aquaculture Research, 34: 93-95.

Mutayoba, S.K. Mutayoba, B.M.; Okot, P. 2003. The performance of growing pullets fed diets with varying energy and leucaena leaf meal levels. Livestock Reserch for Rural Development, 15: 139-148.
Oliveira, A.B. 2008. Germinação de semente de leucena (Leucaena leucocephala). Revista de Biologia e Ciências da Terra, 8: 166-172.

Oliveira, P.B.; Murakami, A.E.; Garcia, E.R.M. 2000. Influência de fatores antinutricionais da leucena (Leucaena leucocephala e Leucaena cunningans) e do feijão guandu (Cajanus cajan) sobre o epitélio intestinal e o desempenho de frangos de corte. Revista Brasileira de Zootecnia, 29: 1759-1769.

Pascual, F.P.; Penãflorida, V. 1979. The extraction of mimosine from ipil-ipil (Leucaena leucocephala) by soaking in water. Aquaculture, 3: 4-6.

Pereira-Filho, M. 1995. Alternativas para a alimentação de peixes em cativeiro, p. 75-82. In: Val, L.A. \& Honczark, A. (Eds). Criando peixes na Amazônia. Instituto Nacional de Pesquisas da Amazônia, Manaus, Amazonas.

Pires, N.M.; Prates, H.T.; Pereira-Filho, I.A.; Oliveira, R.S.; Faria, T.C.L. 2001. Atividade alelopática da leucena sobre espécies de plantas daninhas. Scientia Agricola, 58: 61-65.

Prates, H.T.; Paes, J.M.V.; Pires, M.N.; Pereira-Filho, I.A.; Magalhães, P.C. 2000. Efeito do extrato aquoso de leucena na germinação e no desenvolvimento do milho. Pesquisa Agropecuária Brasileira, 35: 62-68.

Rocha, A.S. 2004. Substituição do farelo de soja por feno de leucena (Leucaena leucocephala) na alimentação de tilápias (Oreochromis niloticus). Monografia de graduaçáo, Universidade Federal do Piauí. 49pp.

Santigo, C.B.; Aldaba, M.B.; Laron, M.A.; Reyes, O.S. 1988. Reproductive performance and growth of Nile tilapia (Oreochromis niloticus) broodstock fed diets containing Leucaena leucocephala leaf meal. Aquaculture, 70: 53-61.

Santos, E.L.; Ludke, L.M.; Ramos, A.M.; Barbosa, J.M.; Ludke, J.B.; Rabelo, C.B. 2009. Digestibilidade de subprodutos da mandioca pela tilápia do Nilo. Revista Brasileira de Ciência Rural, 4: 358-362.

Scapinello, C.; Furlan, A.C.; Jobim, C.C.; Faria, H.G.; Figueiredo, D.F.; Hernandes, A.B. 2000. Valor nutritivo e utilização do feno de leucena (Leucaena leucocephala cv. Cunningham) para coelhos em crescimento. Acta Scientiarum, 22: 829-833.

Segundo, L.F.L.; Araripe, M.N.B.A.; Lopes, J.B. 2006. Substituição do farelo de soja pelo feno de leucena na alimentaçáo de alevinos de tilápia. Revista Científica Produção Animal, 8: 28:34.

Silva, L.X.; Figueiredo, M.V.B.; Silva, G.A.; Goto, B.T.; Oliveira, J.P.; Burity, H.A. 2007. Fungos micorrízicos arbusculares em áreas de plantio de leucena e sabiá no estado de Pernambuco. Revista Árvore, 31: 76-82.

Silva, J.A.M.; Pereira-Filho, M.; Oliveira-Pereira, M.I. 2003. Frutos e sementes consumidos pelo tambaqui, Colossoma macropomum (Cuvier, 1818) incorporados em raçóes. Digestibilidade e velocidade de transito pelo trato gastrointestinal. Revista Brasileira de Zootecnia, 32: 2-12.

Soares, C.M.; Hayashi, C.; Furuya, V.R.B.; Furuya, W.M.; Galdioli, E.M. 2000. Substituição parcial e total da proteína do farelo de canola na alimentação de alevinos de piavuçu (Leporinus macrocephalus, L.). Revista Brasileira de Zootecnia, 29: 15-22. 
Soares, C.M.; Hayashi,C.; Faria, A.C.E.A.; Furuya, W.M. 2001. Substituiçáo da Proteína do Farelo de Soja pela Proteína do Farelo de Canola em dietas para a tilápia do nilo (Oreochrmis niloticus) na fase de crescimento. Revista Brasileira de Zootecnia, 30: 1172-1177.

Tangendjaja, B.; Lowry, J.B.; Wills, R.B.H. 1994. Optimisation of conditions for the degradation of mimosine in Leucaena leucocephala leaf. Science Food Agricola, 35: 613-616.

Terrazas, W.D.M.; Pereira-Filho, M.; Oliveira-Pereira, M.I. 2002. Efeito da farinha de resíduo de peixe e de frango no desempenho e na composição corporal de juvenis de tambaqui, Colossoma macropomum (CUVIER, 1818). Acta Amazonica, 32: 155-162.

Vogt, G., Quinitio, E.T.; Pascual, F.P. 1986. Leucaena leucocephala leaves in formulated feed for Penaeus monodon: a concrete example of the application of histology in nutririon research. Aquaculture, 59: 209-234.

Wee, K.L.; Wang, S.S. 1987. Nutritive value of Leucaena leaf meal in pelleted feed for Nile tilapia. Aquaculture, 62: 97-108.

Recebido em 07/02/2012

Aceito em 14/06/2012 